\title{
In vitro antagonistic activity of Trichoderma harzianum and T. viride strains compared to carbendazim fungicide against the fungal phytopathogens of Sorghum bicolor (L.) Moench
}

Mohamed Taha Yassin * (1), Ashraf Abdel-Fattah Mostafa and Abdulaziz Abdulrahman Al-Askar

\begin{abstract}
Background: High losses of sorghum crops due to fungal diseases, such as grain mold and stalk rot, are economically harmful and cause increased use of environmentally damaging chemical fungicides, which also are detrimental to human health. Hence, finding safe and effective ways to manage fungal diseases of sorghum is urgently needed.

Results: In the present study, the antagonistic activities of Trichoderma viride and T. harzianum against different pathogenic fungal strains were evaluated in vitro using a dual culture assay. Furthermore, the anti-mycotic activity of Trichoderma spp. culture filtrates was evaluated against different fungal strains using a food poisoning technique. Additionally, the antifungal activities of ethyl acetate extracts of T. viride and T. harzianum against different pathogens were evaluated using a disk diffusion method. As indicated by the dual culture assay, T. harzianum suppressed 66.8, $69.5,68.7,54.6,84.12$, and $71.39 \%$ of the mycelial growth of Curvularia lunata, Exserohilum rostratum, Fusarium chlamydosporum, F. incarnatum, F. proliferatum, and Macrophomina phaseolina, respectively. T. viride was more effective for controlling the growth of these pathogens, inhibiting 81.0, 89.0, 63.0, 70.7, 84.4, and 71.8\% of mycelial growth, respectively. Both E. rostratum and M. phaseolina showed resistance to carbendazim fungicide at all tested concentrations, whereas the fungicidal concentrations of carbendazim against C. Iunata, F. chlamydosporum, and F. incarnatum strains were $2.50,1.50$, and $2.00 \mathrm{ppm}$, respectively. Furthermore, F. proliferatum was sensitive to carbendazim fungicide at all tested concentrations. Antifungal assays of the ethyl acetate extracts of T. viride and T. harzianum indicated the potent activity of these extracts against fungal phytopathogens with different susceptibility patterns. F. chlamydosporum was the most sensitive to the extracts of T. viride and T. harzianum with minimum inhibitory concentrations of 0.5 and $1.0 \mathrm{mg} /$ disk, respectively.
\end{abstract}

Conclusion: The potent suppression of sorghum phytopathogens by T. viride and T. harzianum makes them potential sources of safe and effective natural fungicides compared to carbendazim fungicide.

Keywords: Antagonism, Trichoderma, Sorghum, Fungal phytopathogens, Dual culture, Carbendazim, Mycoparasitism

*Correspondence: myassin2.c@ksu.edu.sa

Botany and Microbiology Department, College of Science, King Saud University, P.O. 2455, Riyadh 11451, Saudi Arabia

\begin{abstract}
Background
Ninety percent of global sorghum crops are grown in developing countries on the Asian and African continents (FAO 2018). Fusarium phytopathogens cause many diseases of sorghum, including grain mold and stalk rot (Funnell-Harris et al. 2016). Lower crop yields may be due to the degradation of sorghum vascular tissues by
\end{abstract}


fungal phytopathogens that obstruct the transfer of nutrients and water to the plant (Costa et al. 2019). Fusarium chlamydosporum, F. incarnatum, and $F$. proliferatum were reported as the fungal strains most frequently isolated from diseased sorghum plants (Kelly et al. 2017). Furthermore, these Fusarium strains are reported to produce groups of mycotoxins, such as the trichothecenes and fumonisins (Munkvold 2017). Mycotoxins are secondary metabolites produced by fungal phytopathogens, which cause morbidity and mortality in humans and animals (Egbuta et al. 2007). The fungal pathogen Macrophomina phaseolina, which causes charcoal rot disease of sorghum, causes a $30-40 \%$ loss in crop yields, annually (Prabhu et al. 2012). M. phaseolina infects sorghum plants at all stages of growth and causes the formation of brown lesions on stems and roots (Ghosh et al. 2018). Furthermore, the production of dark, hardened mycelia, called sclerotia, by $M$. phaseolina makes it difficult to be controlled (Sharma et al. 2014). Yago et al. (2011) stated that Curvularia lunata is the most predominant fungal strain isolated from sorghum and finger millet seeds, whereas Little et al. (2012) reported Fusarium spp. and Curvularia spp. as the most prevalent grain mold pathogens isolated from sorghum worldwide. Furthermore, Girish et al. (2004) demonstrated that Exserohilum rostratum and C. lunata are causative agents of grain mold diseases of sorghum, resulting in seed rot and reduced seed germination. Chemical fungicides, such as carbendazim, are used to control grain mold diseases of sorghum (Das et al. 2012), but their use is problematic because of their harmful effects on human and animal health (Kumar and Ashraf 2017). Recently, use of biological control agents, including Trichoderma spp., in the management of plant diseases has been implemented to avoid the toxic effects of chemical pesticides (Naher et al. 2014). Trichoderma spp. are ubiquitous soil-borne Ascomycetes that reproduce asexually and can be found in all soil habitats (Singh et al. 2014). The efficacy of using Trichoderma spp. in the biocontrol of fungal phytopathogens may be due to various mechanisms, including the production of volatile and nonvolatile active compounds (Kumar et al. 2019), competition for nutrients with fungal pathogens (Hermosa et al. 2013), and the mycoparasitic action of lytic enzymes, such as $\beta$-1,3-glucanase and chitinase, which degrade the cell walls of fungal pathogens (Ojha and Chatterjee 2011).

Because of the huge economic losses caused by fungal diseases that affect sorghum crops and the harmful effects of using pesticides, searching for effective biological control agents is needed. Accordingly, the objective of the present study was to evaluate the antagonistic efficacy of T. harzianum and T. viride strains compared to carbendazim fungicide against six fungal phytopathogens that cause serious fungal diseases of sorghum. Moreover, the mechanism of the fungal antagonism of Trichoderma spp. against different fungal pathogens was also evaluated.

\section{Methods \\ Fungal strains}

Phytopathogenic fungal strains used in the present study, Curvularia lunata ATCC 14595, Exserohilum rostratum ATCC 18,550, Fusarium chlamydosporum ATCC 200468, F. incarnatum ATCC 24387, $F$. proliferatum ATCC 208803, and Macrophomina phaseolina ATCC 64334, were obtained from the culture collection of Botany and Microbiology Department, College of Science, King Saud University, Saudi Arabia. Two antagonistic strains (Trichoderma viride ATTC 16646 and T. harzianum 20847) were tested for their antagonistic activity against different fungal phytopathogens. The fungal strains were freshly subcultured on potato dextrose agar (PDA) slants for 5 days at $28 \pm 1{ }^{\circ} \mathrm{C}$ and then stored in the refrigerator until further use.

\section{Evaluation of fungal antagonistic activity (dual culture technique)}

A dual culture technique was used to evaluate the antagonistic efficacy of T. harzianum and T. viride against different strains of sorghum phytopathogenic fungi (Awad et al. 2018). Eight-millimeter mycelial disks of the fungal phytopathogens and antagonistic strains were inoculated onto PDA plates concurrently. The phytopathogens $(C$. lunata, E. rostratum, F. chlamydosporum, F. incarnatum, F. proliferatum, and M. phaseolina) were also cultured onto PDA plates as controls and incubated at $28 \pm 1{ }^{\circ} \mathrm{C}$ for 5 days. The radial growth of the pathogenic strains on both treated and control plates was measured using Vernier calipers. The growth inhibition percentages are calculated according to the following equation:

$$
\text { \%inhibition }=(A-B) / A \times 100
$$

where $A$ is the diameter of the phytopathogen colonies on control plates and $B$ is the diameter of phytopathogen colonies on treated plates. The experiment was done in triplicate, and the results were expressed as a mean of triplicates \pm standard error.

\section{Antifungal potency of culture filtrates of antagonistic strains}

The antifungal efficiency of $T$. harzianum and T. viride against different phytopathogenic strains was estimated using a food poisoning technique. The two tested Trichoderma isolates were subcultured in potato dextrose broth medium and incubated at $28 \pm 1{ }^{\circ} \mathrm{C}$ for 5 days on an orbital shaker $(150 \mathrm{rpm})$. The culture filtrates of 
Trichoderma spp. isolates were harvested by filtration using double layers of muslin to attain cell-free filtrates. Centrifugation of the cell-free filtrates was conducted at $9000 \mathrm{rpm}$ for $10 \mathrm{~min}$ to remove fungal spores that may obstruct the sterilization membranes. Finally, sterilization of the Trichoderma spp. filtrates was conducted using Millipore filters $(22 \mu \mathrm{m})$ (Sreedevi et al. 2011). Filtrates of the two Trichoderma spp. were added to PDA medium to attain a final concentration of $25 \%$ in Petri dishes. The treated plates were inoculated at the center with $8-\mathrm{mm}$ disks of different strains of pathogenic fungi. Control plates were also inoculated with $8-\mathrm{mm}$ mycelial disks of different fungal pathogens. Both treated and control groups were incubated at $28 \pm 1{ }^{\circ} \mathrm{C}$ for 5 days, and the growth diameters of the fungal pathogens were appraised using Vernier calipers. The estimated percentage inhibition of growth is calculated according to the following equation:

$$
\text { \%inhibition }=(A-B) / A \times 100
$$

where $A$ is the radial growth of the fungal pathogens in the control group and $B$ is the radial growth of the fungal pathogens in the treated group.

Detection of mycoparasitism using slide culture technique Freshly prepared PDA medium was sectioned using a sterilized cutter and placed on sterile glass slides. The agar cubes were inoculated with the fungal pathogen from one side and the antagonistic strain (T. harzianum or $T$. viride) from the opposite side. The slides were then incubated at $28 \pm 1{ }^{\circ} \mathrm{C}$ for 5 days. When the PDA cubes were removed, the mycelia were stained using lactophenol cotton blue, and coverslips were placed over the slides for microscopic examination. Mycoparasitic relationships between the antagonistic strains and phytopathogens were examined using a light microscope $(40 \times)$ (Naglot et al. 2015).

\section{Antifungal efficacy of standard fungicide (carbendazim)}

Antifungal efficacy of carbendazim, a commonly used fungicide against different sorghum phytopathogens, was evaluated using a food poisoning technique. The sterile PDA medium was amended by different concentrations of carbendazim fungicide $(0.50,1.00,1.50,2.00,2.50$, and $3.00 \mathrm{ppm})$. PDA plates were inoculated with $8-\mathrm{mm}$ mycelial disks of the fungal pathogens and incubated at $28 \pm 1{ }^{\circ} \mathrm{C}$ for 5 days (Anand et al. 2010). A control group of plates was inoculated with 8-mm mycelial disks and incubated at $28 \pm 1{ }^{\circ} \mathrm{C}$ for 5 days. The radial growth of the phytopathogens, on both the control and treated plates, was estimated using Vernier calipers, and the growth inhibition percentage is measured according to the following formula:

$$
\text { \%inhibition }=(A-B) / A \times 100
$$

where $A$ is the radial growth diameter of phytopathogens in the control group and $B$ is the radial growth diameter of phytopathogens on the treated plates.

\section{Preparation of the two Trichoderma spp. crude extracts}

Extraction was conducted using ethyl acetate solvent, as described by Chen et al. (2018). Both T. harzianum and T. viride were subcultured onto freshly prepared potato dextrose broth medium ( $1 \mathrm{l}$ ) and incubated on a rotatory shaker for 7 days at $28 \pm 1{ }^{\circ} \mathrm{C}$. The solid mycelial growth was separated by filtration using Whitman filter paper no.1. The fungal metabolites were extracted from the culture filtrates using ethyl acetate solvent. An aliquot of the two Trichoderma cultures was mixed with ethyl acetate solvent at a ratio of 1:0.5. Then, the mixture was mixed vigorously and left for $2 \mathrm{~h}$ in a separation funnel. Collection of the organic phase was conducted, and the extract was eluted over anhydrous sodium sulfate $\left(\mathrm{Na}_{2} \mathrm{SO}_{4}\right)$ for complete removal of water from the solvent. Finally, the extracts were allowed to dry using a rotatory evaporator, and the yield of the crude extract was recorded (Jantarach and Thanaboripat 2010). The yields of T. harzianum and T. viride were 74.5 and $86.7 \mathrm{mg} / \mathrm{l}$, respectively.

\section{Antifungal assay of the ethyl acetate extracts of $T$. viride and $T$. harzianum}

Antifungal efficacy of the two Trichoderma spp. extracts against different fungal strains was evaluated using the disk diffusion method. Ten milliliters of PDA medium was poured into sterile Petri dishes as a basal medium, followed by the addition of $15-\mathrm{ml}$ seeded medium that had previously been inoculated with the fungal spore suspension. Seeded medium was prepared by adding 1 - $\mathrm{ml}$ aliquots of spore suspension $\left(10^{6} \mathrm{spores} / \mathrm{ml}\right)$ of each pathogenic fungal strain to each $100 \mathrm{ml}$ of PDA medium. The ethyl acetate extracts of both T. harzianum and T. viride were dissolved in dimethyl sulfoxide to attain a final concentration of $10 \mathrm{mg} /$ disk. Sterile filter paper disks ( $8 \mathrm{~mm}$ diameter) were loaded with the different extracts and placed over the solidified agar medium. Terbinafine (an antifungal compound) at a concentration of $50 \mu \mathrm{g} /$ disk was used as a positive control. The plates were incubated at $28 \pm 1{ }^{\circ} \mathrm{C}$ for 5 days, and the diameters of the inhibition zones were measured using Vernier calipers (Yassin et al. 2020a).

\section{Determination of minimum inhibitory concentration of Trichoderma spp. ethyl acetate extracts}

The lowest concentrations of T. harzianum and T. viride extracts required to inhibit mycelial growth of the fungal sorghum pathogens were recorded as minimum 
inhibitory concentrations (MICs). The MICs of $T$. viride and T. harzianum against different fungal phytopathogenic strains were detected using the disk diffusion method. Sterile filter paper disks $(8 \mathrm{~mm})$ were impregnated with different concentrations of $T$. viride and $T$. harzianum extracts $(0.25,0.50,1.00,2.00,4.00$, and $8.00 \mathrm{mg} /$ disk) and placed over previously prepared PDA plates seeded with microbial spore suspensions $\left(10^{6} \mathrm{spores} / \mathrm{ml}\right)$. The plates were kept in an incubator at $28 \pm 1{ }^{\circ} \mathrm{C}$ for 5 days, and the diameters of the zones of inhibition were measured using Vernier calipers. The lowest concentrations exhibiting anti-mycotic activity were registered as MICs (Yassin et al. 2020b).

\section{Statistical analysis}

GraphPad Prism 5.0 (GraphPad Software, Inc., La Jolla, CA, USA) was used to statistically analyze the data via one-way analysis of variance. The data are presented as the mean of triplicates \pm standard error.

\section{Results}

Antagonistic activity of Trichoderma spp. against fungal phytopathogens

Both of the antagonistic fungal species, T. viride and $T$. harzianum, exhibited inhibitory effects against fungal pathogens of sorghum (Fig. 1). T. harzianum isolates showed the highest antagonistic activity against F. proliferatum, whereas $T$. viride demonstrated the highest activity against $E$. rostratum, with relative inhibition percentages of 84 and $89 \%$, respectively (Fig. 2). The antagonistic activity of the $T$. viride isolates against $E$. rostratum was significantly higher $(P \leq 0.001)$ than that of $T$. harzianum. Furthermore, the mycelial inhibition of $C$. lunata and $F$. incarnatum on plates treated with $T$. viride was significantly higher $(P \leq 0.01)$ than on those treated with T. harzianum. However, T. harzianum exhibited significant inhibitory activity against $F$. chlamydosporum $(P \leq 0.01)$ compared with $T$. viride. By contrast, $T$. harzianum and T. viride demonstrated nonsignificant antagonistic activity $(P>0.05)$ against isolates of $F$. proliferatum and M. phaseolina.

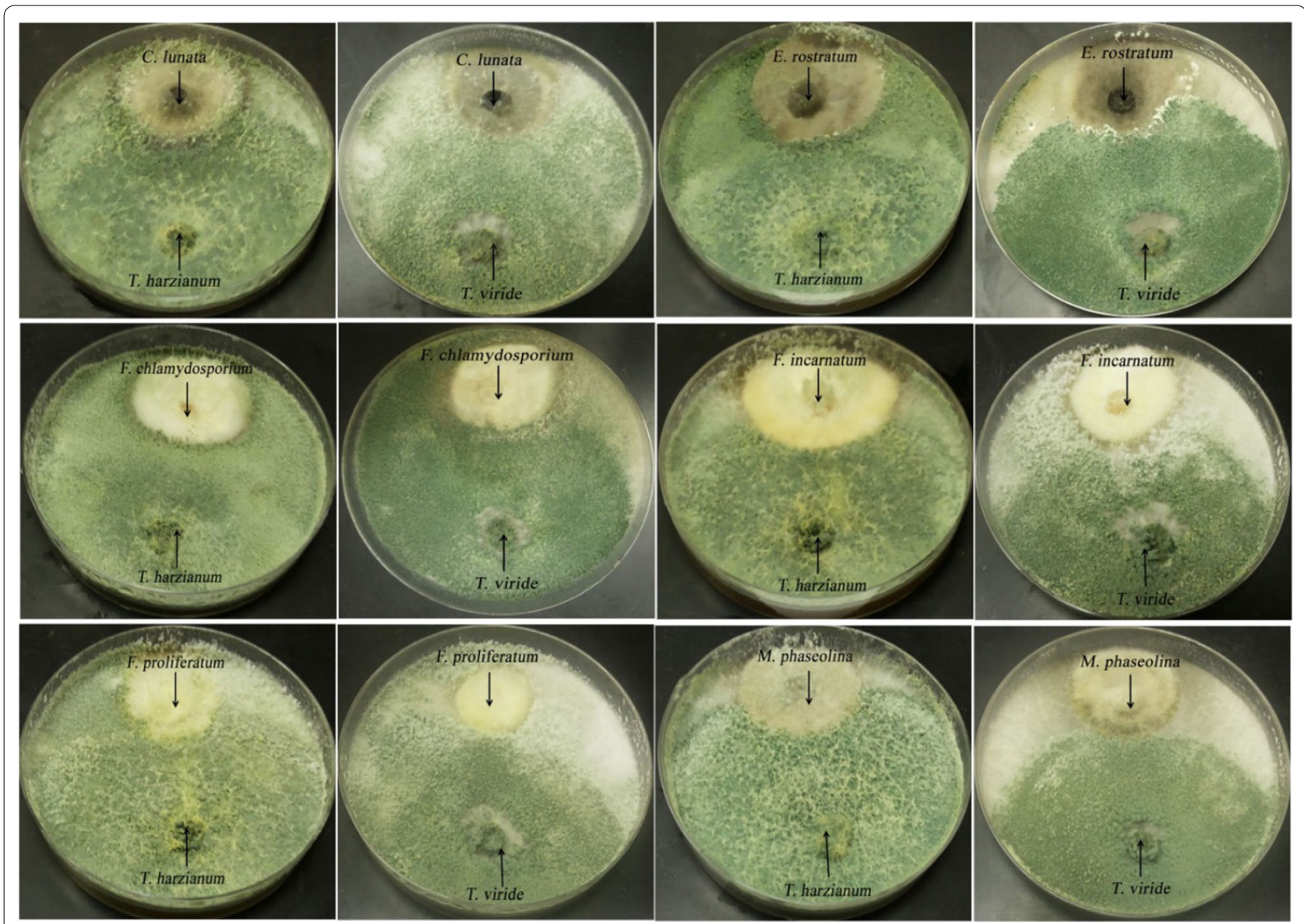

Fig. 1 Dual culture assay of T. viride and T. harzianum against fungal phytopathogens of sorghum 


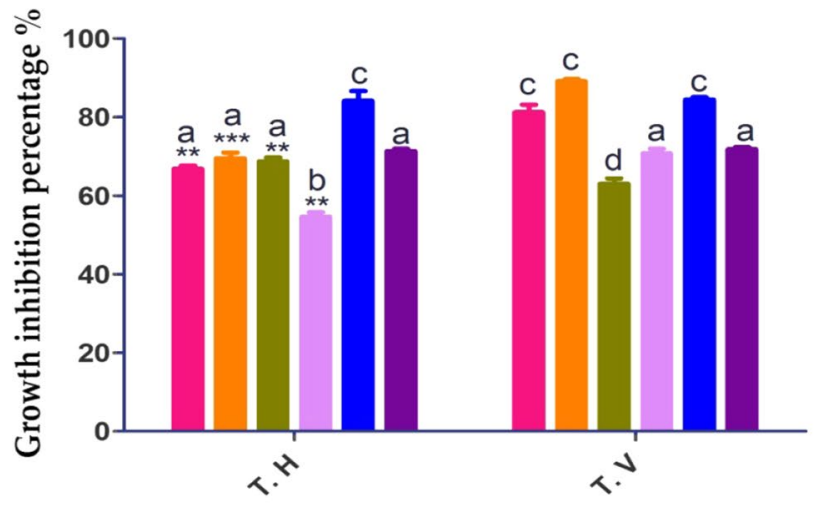

Curvularia lunata

Exserohilum rostratum

Fusarium chlamydosporum

Fusarium incarnatum

Fusarium proliferatum

Macrophomina phaseolina

Antagonistic strains

Fig. 2 Antagonistic activity of T. viride and T. harzianum against different fungal phytopathogens. *Asterisks indicate that the antagonistic activity of T. harzianum against Curvularia lunata, Exserohilum rostratum, Fusarium chlamydosporum, and Fusarium incarnatum was significantly different compared with that of T. viride $\left({ }^{* *} P \leq 0.001,{ }^{* *} P \leq 0.01,{ }^{*} P \leq 0.05\right) .{ }^{*}$ Different letters indicate that values were significantly different $(P \leq 0.05)$

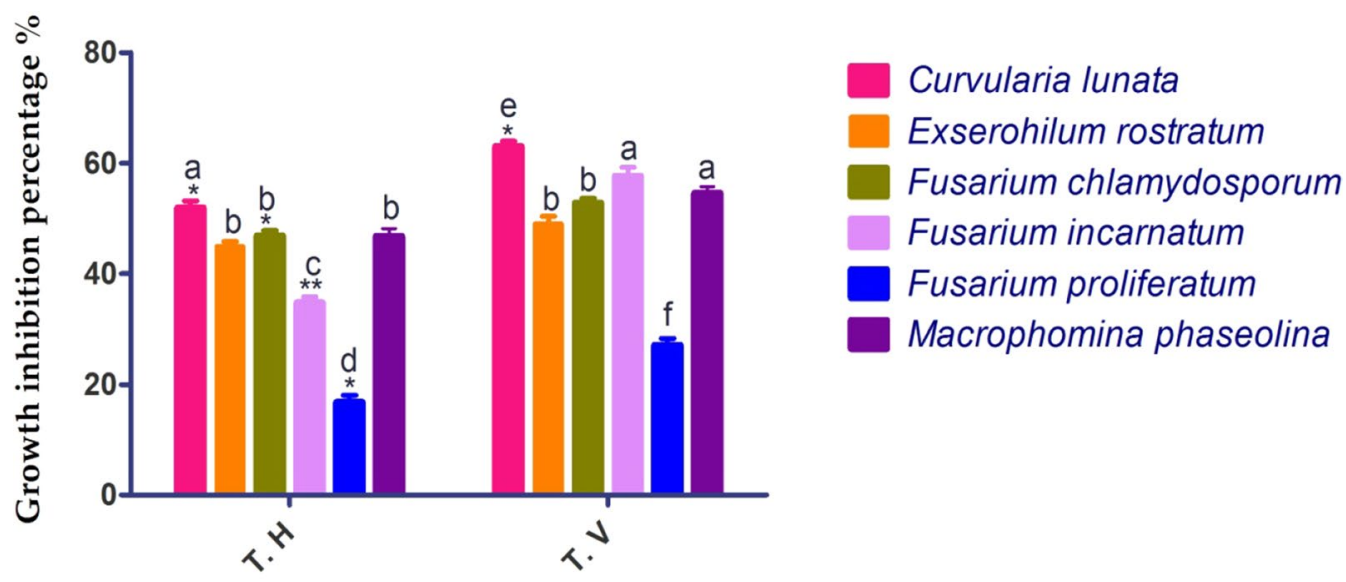

Culture filtrates of antagonisitc strains

Fig. 3 Anti-mycotic activity of culture filtrates of T. viride and T. harzianum against different fungal phytopathogens. * Asterisks indicate that the anti-mycotic activity of the culture filtrate of T. harzianum against Curvularia lunata, Fusarium chlamydosporum, Fusarium incarnatum, and Fusarium proliferatum was significantly different compared with that of T. viride $\left({ }^{* *} P \leq 0.01,{ }^{*} P \leq 0.05\right)$. ${ }^{*}$ Different letters indicated that values were significantly different $(P \leq 0.05)$

Antifungal efficacy of Trichoderma spp. culture filtrates Antifungal potency of $T$. viride culture filtrates against different pathogenic fungal strains was higher than that of $T$. harzianum. The culture filtrates of T. harzianum and $T$. viride exhibited the highest inhibitory activities, 51.9 and $63 \%$, respectively, against C. lunata, whereas the lowest one was detected against $F$. proliferatum, with relative inhibition percentages of 16.8 and $27 \%$, respectively. The percentage of growth inhibition in C. lunata, F. chlamydosporum, and F. proliferatum on plates treated with culture filtrates of $T$. viride was significantly higher $(P \leq 0.05)$ than that on plates treated with $T$. harzianum filtrate. Furthermore, $T$. viride filtrates suppressed the mycelial growth of $F$. incarnatum at a relative percentage of $57.67 \%$, which was significantly higher $(P \leq 0.01)$ than that of the $T$. harzianum filtrate (Fig. 3). By contrast, the suppression $M$. phaseolina and E. rostratum mycelial growth on plates treated with the $T$. viride filtrate was nonsignificant $(P>0.05)$ compared with plates treated with the $T$. harzianum filtrate.

\section{Mycoparasitic relationships between antagonistic strains and phytopathogens}

Mycoparasitic relationships between antagonistic strains ( $T$. viride and $T$. harzianum) and fungal 
phytopathogens of sorghum were examined using a slide culture technique. T. harzianum demonstrated mycoparasitism of C. lunata, F. chlamydosporum, $F$. proliferatum, and $M$. phaseolina, whereas no mycoparasitism of $E$. rostratum and $F$. incarnatum was detected. Microscopic investigations of the mycoparasitic relationships between antagonistic strains and fungal phytopathogens demonstrated that $T$. viride showed non-parasitic actions against different pathogenic fungal strains. Mode of action of T. harzianum as a biological control agent against $C$. lunata, F. chlamydosporum, F. proliferatum, and M. phaseolina included adhesion to the pathogen hyphae, penetration of the fungal pathogen hyphae through the formation of appressoria, coiling of the Trichoderma harzianum hyphae around the hyphae of the different fungal pathogens, and lysis of the fungal mycelium.

\section{Detection of antifungal efficacy of carbendazim against sorghum phytopathogens}

Fusarium proliferatum was the fungal isolate most sensitive to the carbendazim fungicide at all tested concentrations, whereas E. rostratum and M. phaseolina were resistant to carbendazim, as shown in Table 1. At a concentration of $0.50 \mathrm{ppm}$, carbendazim inhibited the mycelial growth of C. lunata, F. chlamydosporum, and $F$. incarnatum by $33.8,44.5$, and $55.9 \%$, respectively. Microbicidal activity of carbendazim against $F$. chlamydosporum, $F$. incarnatum, and $C$. lunata was detected at concentrations of 1.50, 2.00, and $2.50 \mathrm{ppm}$, respectively.

\section{Antifungal activity of the ethyl acetate extract} of Trichoderma spp. against fungal pathogens

The ethyl acetate extract of $T$. viride exhibited a significant antimicrobial activity $(P \leq 0.05)$ against $C$. lunata and $E$. rostratum, compared with the control (terbinafine), with suppression zone diameters of 16.9 and $20.2 \mathrm{~mm}$, respectively. Furthermore, the ethyl acetate extract of $T$. viride exhibited antifungal efficacy against F. chlamydosporum, F. incarnatum, F. proliferatum, and M. phaseolina, with suppression zones of 21.3, 18.8, 19.5 , and $12.5 \mathrm{~mm}$, respectively (Fig. 4). However, differences in the antifungal activities of $T$. viride ethyl acetate extracts and terbinafine against $F$. incarnatum and $M$. phaseolina were nonsignificant $(P>0.05)$. C. lunata and $M$. phaseolina were significantly susceptible $(P \leq 0.05)$ to the $T$. harzianum ethyl acetate extracts, compared with the control, with inhibition zone diameters of 18.3 and $12.53 \mathrm{~mm}$, respectively. Furthermore, the T. harzianum ethyl acetate extract exhibited antimicrobial activity against $E$. rostratum, F. chlamydosporum, F. incarnatum, and $F$. proliferatum, with suppression zones measuring $11.39,17.56,13.45$, and $15.55 \mathrm{~mm}$, respectively. F. chlamydosporum was the most sensitive one to the ethyl acetate extracts of $T$. viride and T. harzianum, with inhibition zone diameters of 21.3 and $17.56 \mathrm{~mm}$, respectively.

\section{Detection of minimum inhibitory concentration of Trichoderma spp. ethyl acetate extracts}

The minimum inhibitory concentration (MIC) was calculated as the lowest concentration of the Trichoderma spp. ethyl acetate extract required to exhibit antifungal activity. MIC values were evaluated for $F$. chlamydosporum strain, as it showed the highest sensitivity to the ethyl extracts of T. viride and T. harzianum. Their ethyl acetate extracts exhibited antifungal potency against $F$. chlamydosporum, with MIC values of 0.5 and $1.0 \mathrm{mg} /$ disk, respectively (Fig. 5).

Table 1 Antifungal efficacy of carbendazim fungicide against different fungal phytopathogens of sorghum

\begin{tabular}{lllllll}
\hline Carbendazim & \multicolumn{6}{l}{ Mycelial growth of different pathogenic strains, mm (mycelial inhibition percentage, \%) } \\
\cline { 2 - 7 } Concn. (ppm) & C. lunata & E. rostratum & F. chlamydosporum & F. incarnatum & F. proliferatum & M. phaseolina \\
\hline 0.00 & $64.4 \pm 0.24^{\mathrm{a}}(0.00 \%)$ & $60.8 \pm 0.13^{\mathrm{a}}(0.00 \%)$ & $69.2 \pm 0.21^{\mathrm{a}}(0.00 \%)$ & $78.4 \pm 0.65^{\mathrm{a}}(0.00 \%)$ & $74.9 \pm 0.43^{\mathrm{a}}(0.00 \%)$ & $56.7 \pm 0.24^{\mathrm{a}}(0.00 \%)$ \\
0.50 & $42.6 \pm 0.45^{\mathrm{b}}(33.8 \%)$ & $78.3 \pm 0.39^{\mathrm{b}}(0.00 \%)$ & $27.4 \pm 0.53^{\mathrm{b}}(44.5 \%)$ & $34.5 \pm 0.34^{\mathrm{b}}(55.9 \%)$ & $0.00 \pm 0.00^{\mathrm{b}}(100 \%)$ & $74.3 \pm 0.32^{\mathrm{b}}(0.00 \%)$ \\
1.00 & $32.9 \pm 0.32^{\mathrm{c}}(48.9 \%)$ & $71.7 \pm 0.43^{\mathrm{c}}(0.00 \%)$ & $12.8 \pm 0.47^{\mathrm{c}}(81.5 \%)$ & $21.7 \pm 0.18^{\mathrm{c}}(72.3 \%)$ & $0.00 \pm 0.00^{\mathrm{b}}(100 \%)$ & $72.2 \pm 0.29^{\mathrm{b}}(0.00 \%)$ \\
1.50 & $23.2 \pm 0.53^{\mathrm{d}}(63.9 \%)$ & $69.8 \pm 0.71^{\mathrm{c}}(0.00 \%)$ & $0.00 \pm 0.00^{\mathrm{d}}(100 \%)$ & $9.5 \pm 0.24^{\mathrm{d}}(87.8 \%)$ & $0.00 \pm 0.00^{\mathrm{b}}(100 \%)$ & $69.8 \pm 0.76^{\mathrm{b}}(0.00 \%)$ \\
2.00 & $13.7 \pm 0.64^{\mathrm{e}}(78.7 \%)$ & $67.6 \pm 0.43^{\mathrm{c}}(0.00 \%)$ & $0.00 \pm 0.00^{\mathrm{d}}(100 \%)$ & $0.00 \pm 0.00^{\mathrm{e}}(100 \%)$ & $0.00 \pm 0.00^{\mathrm{b}}(100 \%)$ & $64.3 \pm 0.15^{\mathrm{c}}(0.00 \%)$ \\
2.50 & $0.00 \pm 0.00^{\mathrm{f}}(100 \%)$ & $63.9 \pm 0.71^{\mathrm{d}}(0.00 \%)$ & $0.00 \pm 0.00^{\mathrm{d}}(100 \%)$ & $0.00 \pm 0.00^{\mathrm{e}}(100 \%)$ & $0.00 \pm 0.00^{\mathrm{b}}(100 \%)$ & $61.9 \pm 0.56^{\mathrm{c}}(0.00 \%)$ \\
3.00 & $0.00 \pm 0.00^{f}(100 \%)$ & $61.5 \pm 0.12^{\mathrm{d}}(0.00 \%)$ & $0.00 \pm 0.00^{\mathrm{d}}(100 \%)$ & $0.00 \pm 0.00^{\mathrm{e}}(100 \%)$ & $0.00 \pm 0.00^{\mathrm{b}}(100 \%)$ & $57.1 \pm 0.14^{\mathrm{d}}(0.00 \%)$ \\
\hline
\end{tabular}

Different superscript letters in the same column indicate a significant difference at $P<0.05$

Data are means of results from triplicate experiments \pm standard error 


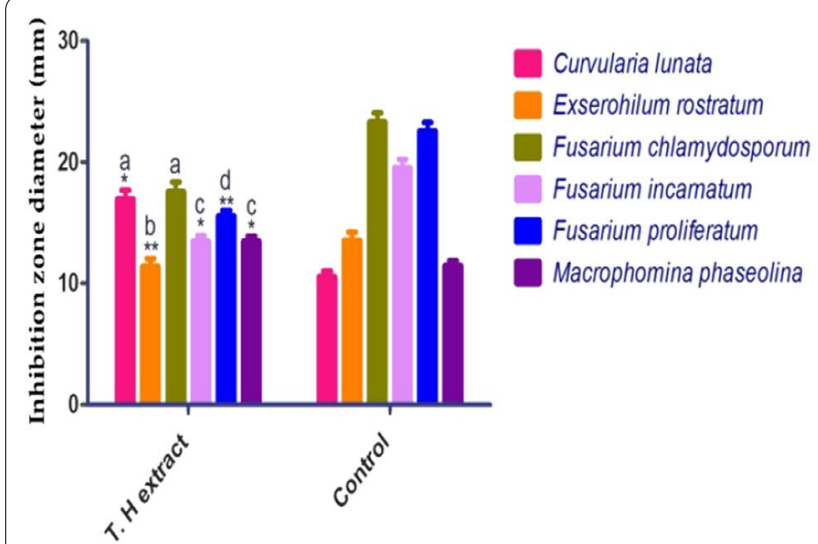

Antifungal potency of T. harzianum ethyl acetate extract

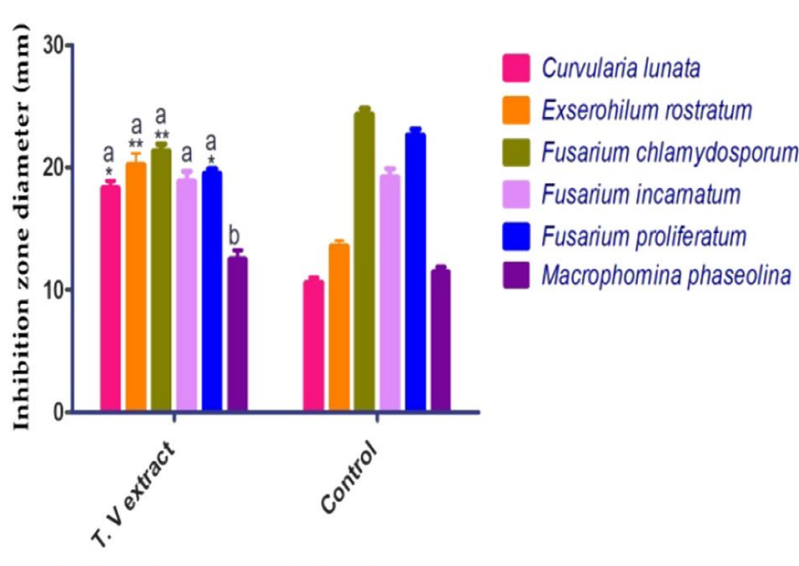

Antifungal potency of $T$. viride ethyl acetate extract

Fig. 4 Antifungal activity of the ethyl acetate extracts of T. viride and T. harzianum against different fungal phytopathogens. ${ }^{*}$ Asterisks indicate that the antifungal efficacy of the extracts was significantly different compared with that of the control (Terbinafine) $\left({ }^{* *} P \leq 0.01,{ }^{*} P \leq 0.05\right)$. ${ }^{*}$ Different letters indicate that values are significantly different $(P \leq 0.05)$

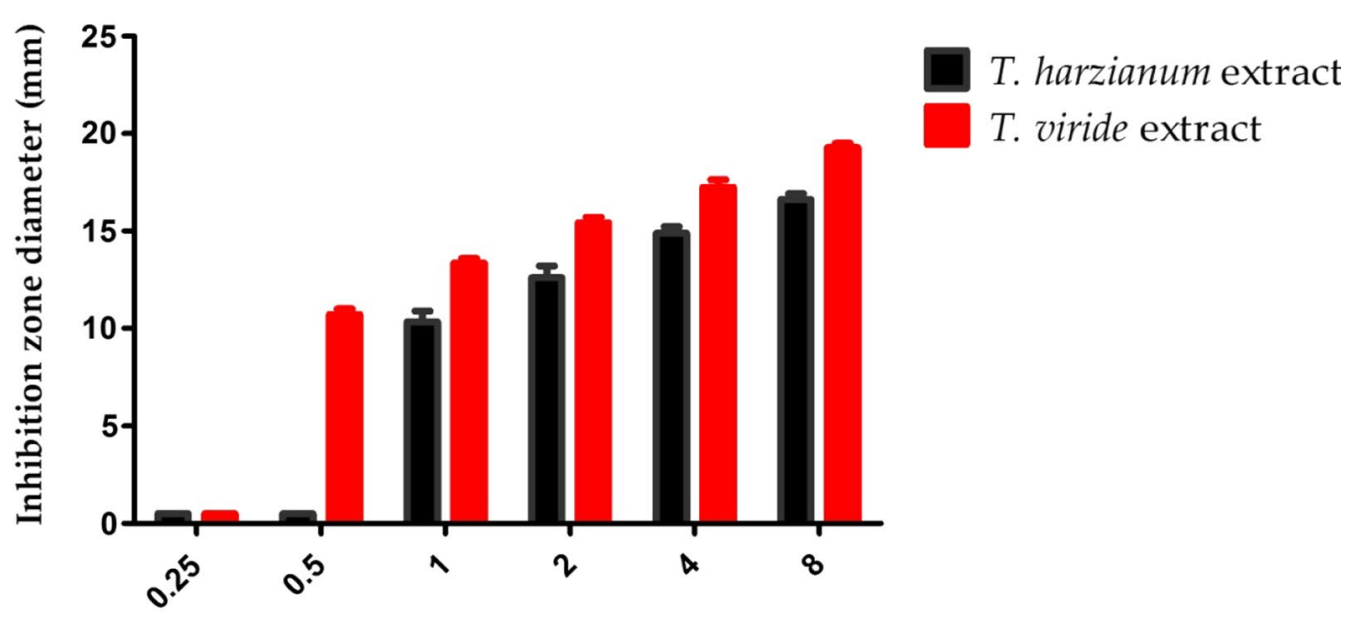

Concnetration of the extract $(\mathrm{mg} / \mathrm{disc})$

Fig. 5 Minimum inhibitory concentration of the ethyl acetate extracts of T. viride and T. harzianum against F. chlamydosporum

\section{Discussion}

The antagonistic activity of $T$. viride and $T$. harzianum strains against different fungal pathogens of sorghum was examined in the present study. A dual culture assay showed that $T$. harzianum and $T$. viride exhibited potential antagonistic activity against the concerned fungal pathogens. T. viride inhibited the mycelial growth of three Fusarium spp. (F. proliferatum, F. incarnatum, and F. chlamydosporum) by $84.4,70.7$, and $63.0 \%$, respectively. The potency of $T$. viride to suppress the fusarial growth was previously confirmed by Abhiram and Masih (2018), who reported that the mycelial growth of $F$. oxysporum in a dual culture assay was inhibited by $65.2-71.0 \%$. Perveen and Bokhari (2012) demonstrated that T. viride and T. harzianum isolates inhibited the mycelial growth of $F$. oxysporum by 66.3 and $56.43 \%$, respectively. Furthermore, T. harzianum and T. viride inhibited the mycelial growth of C. lunata by 66.80 and $81.23 \%$, respectively. Koulagi et al. (2011) stated that T. harzianum and T. viride inhibited $C$. lunata, isolated from discolored rice grains, by 93.50 and $96.44 \%$, respectively. Furthermore, the percentages of mycelial growth inhibition in $M$. phaseolina incurred by T. viride and T. harzianum were 71.84 and $71.39 \%$, respectively. The antagonistic efficacy of Trichoderma spp. against $M$. phaseolina was higher than that detected in the previous study, which showed that $T$. 
viride and T. harzianum inhibited the mycelial growth of M. phaseolina by 46.34 and $48.75 \%$, respectively (Jat and Agalave 2013).

The antagonistic capabilities of Trichoderma spp. against fungal pathogens may be due to the number of mechanisms involving nutrient competition between the antagonistic strains and fungal pathogens, mycoparasitism, production of active secondary metabolites, and degradation of fungal cell walls through the production of cell wall degrading enzymes (Druzhinina et al. 2011). Culture filtrates of $T$. viride showed higher anti-mycotic activities than $T$. harzianum against the fungal phytopathogens studied. The percentages of inhibition in mycelial growth of the tested Fusarium spp. F. incarnatum, F. chlamydosporum, and F. proliferatum were 57.7, 52.8 , and $27.1 \%$, respectively, and this result was according to that of Naglot et al. (2011), who confirmed the potent suppressive effect of a $T$. viride culture filtrate against 21 strains of Fusarium solani, recording mycelial inhibition in the range of 47.5-73.3\%. Furthermore, Chohan et al. (2015) verified the suppressive effect of T. harzianum and T. viride culture filtrates against Alternaria solani, recording mycelial inhibition percentages of 67.8 and $59.6 \%$, respectively.

In the present study, the antagonistic $T$. harzianum strain exerted mycoparasitic behavior against $C$. lunata, F. chlamydosporum, F. proliferatum, and M. phaseolina, through both mechanical and enzymatic actions. The mechanical action of T. harzianum was observed as adhesion, coiling around the pathogen's mycelium, and penetration of the fungal mycelium using an appressorium-like structure, whereas the enzymatic action was demonstrated by lysis of the fungal mycelia. In this respect, mycoparasitism has been recognized as a major mode of action of $T$. harzianum against fungal phytopathogens, thereby exposing its efficiency as a biological control agent (Köhl et al. 2019).

Excessive use of pesticides in the management of fungal diseases of crops disrupts the ecological balance and causes the development of fungal resistant to pesticides (Lari et al. 2014). E. rostratum and M. phaseolina showed resistance to carbendazim fungicide at all of the concentrations tested in the present study. The potent antagonistic effect of $T$. viride and T. harzianum against resistant strains of $E$. rostratum and M. phaseolina supports the use of these bioagents in the formulation of natural pesticides for the successful management of fungal phytopathogens of sorghum. Furthermore, the ethyl acetate extracts of $T$. viride and T. harzianum strains showed anti-mycotic activity against different pathogenic strains with different susceptibility patterns. The ethyl acetate extract of $T$. viride was more effective against $C$. lunata, E. rostratum, F. chlamydosporum, $F$. incarnatum, and $F$. proliferatum, whereas the ethyl acetate extract of $T$. harzianum was more effective against $M$. phaseolina. The potent antifungal efficiency of the ethyl acetate extracts of Trichoderma spp. was confirmed by Jantarach and Thanaboripat (2010), who indicated that the ethyl acetate extract of Trichoderma spp. exerts antifungal activity against Aspergillus flavus, recording suppression zones ranging from 7.60 to $37.00 \mathrm{~mm}$ in diameter. Furthermore, the volatile compounds from Trichoderma spp. had potential antifungal activity against fungal phytopathogens (Abdollahi et al. 2012). Trichoderma spp. release a wide range of volatile compounds such as monoterpenes, alcohols, sesquiterpenes, aldehydes, aromatic compounds, esters, hydrocarbons, and ketones, which are reported to have biological activities (Siddiquee 2014).

\section{Conclusions}

The antagonistic activity of $T$. viride and $T$. harzianum against different fungal phytopathogens of sorghum highlights the potential of using these bioagents to formulate natural and highly effective fungicides. The resistance of E. rostratum and $M$. phaseolina to carbendazim fungicide was recorded in the present study. The potent activity of the ethyl acetate extracts of $T$. viride and T. harzianum against different pathogenic strains of sorghum makes them a potential source of natural and safe fungicides for use against resistant fungal strains particularly.

\section{Abbreviations}

ATCC: American Type Culture Collection; MIC: Minimum inhibitory concentrations; PDA: Potato dextrose agar; T.H:Trichoderma harzianum; T.V:Trichoderma viride.

\section{Acknowledgements}

Author Ashraf A. Mostafa extends his appreciation to the Researchers Supporting Project number (RSP-2021/362), King Saud University, Riyadh, Saudi Arabia.

\section{Authors' contributions}

MTY, AAM, and AAA designed the study, carried out the experiments, and wrote the original draft. MTY analyzed the data statistically. AAM helped in reviewing and editing of the final draft. All authors have read and approved the final manuscript.

\section{Funding}

The funder provided the required chemicals and materials used in the study.

\section{Availability of data and materials}

The datasets used and/or analyzed during the current study are available from the corresponding author on reasonable request.

\section{Declarations}

Ethical approval and consent to participate

Not applicable.

\section{Consent to publish}

Not applicable.

Competing interests

The authors declare that they have no competing interests. 
Received: 22 February 2021 Accepted: 21 August 2021

Published online: 29 August 2021

\section{References}

Abdollahi M, Rahnama K, Marabadi M, Ommati F, Zaker M (2012) The in vitro efficacy of Trichoderma isolates against Pythium aphanidermatum, the causal agent of sugar beet root rot. J Res Agric Sci 8:79-87

Abhiram P, Masih H (2018) In vitro Antagonism of Trichoderma viride against Fusarium oxysporum strains. J Pharmacogn Phytochem 7:2816-2819

Anand T, Chandrasekaran A, Kuttalam S, Senthilraja G, Samiyappan R (2010) Integrated control of fruit rot and powdery mildew of chilli using the biocontrol agent Pseudomonas fluorescens and a chemical fungicide. Biol Control 52:1-7

Awad NE, Kassem HA, Hamed MA, El-Feky AM, Elnaggar MAA, Mahmoud K, Ali MA (2018) Isolation and characterization of the bioactive metabolites from the soil derived fungus Trichoderma viride. Mycology 9:70-80

Chen X, Huang Y, Huang Z (2018) Combination of ethyl acetate extract of Trichoderma hamatum Fermentation Broth and fungicide carbendazim enhances Inhibition against Scleromitrula shiraiana under laboratory conditions. Pak J Zool 50:2239-2247

Chohan S, Perveen R, Abid M, Naz MS, Akram N (2015) Morpho-physiological studies management and screening of tomato germplasm against Alternaria solani the causal agent of tomato early blight. Int J Agric Biol 17:111-118

Costa RV, Simon J, Cota LV, Silva DD, Almeida REM, Lanza FE, Lago BC, Pereira AA, Campos LJM, Figueiredo JEF (2019) Yield losses in off-season corn crop due to stalk rot disease. Pesq Agropec Bras 54:1-10

Das I, Audilakshmi S, Patil J (2012) Fusarium grain mold: the major component of grain mold disease complex in sorghum (Sorghum bicolor L. Moench). Eur J Plant Sci Biotechnol 6:45-55

Druzhinina IS, Seidl-Seiboth V, Herrera-Estrella A, Horwitz BA, Kenerley CM, Monte E, Mukherjee PK, Zeilinger S, Grigoriev IV, Kubicek CP (2011) Trichoderma: the genomics of opportunistic success. Nat Rev Microbiol 9:749-759

Egbuta MA, Mwanza M, Babalola OO (2007) Health risks associated with exposure to filamentous fungi. Int J Environ Res Public Health 14:719

FAO (2018) Statistical pocketbook: world food and agriculture 2018. Food and Agriculture Organization of the United Nations, Rome. http://www.fao. org/3/CA1796EN/ca1796en.pdf. Accessed 16 Mar 2019

Funnell-Harris DL, O'Neill PM, Sattler SE, Yerka MK (2016) Response of sweet sorghum lines to stalk pathogens Fusarium thapsinum and Macrophomina phaseolina. Plant Dis 100:896-903

Ghosh T, Biswas M, Guin C, Roy P (2018) A review on characterization, therapeutic approaches and pathogenesis of Macrophomina phaseolina. Plant Cell Biotechnol Mol Biol 19:72-84

Girish A, Deepti S, Rao V, Thakur R (2004) Detection of seedborne grain mold fungi in sorghum and their control with fungicidal seed treatment. Int Sorghum Millets Newsl 45:31-33

Hermosa R, Rubio MB, Cardoza RE, Nicolás C, Monte E, Gutiérrez S (2013) The contribution of Trichoderma to balancing the costs of plant growth and defense. Int Microbiol 16:69-80

Jantarach J, Thanaboripat D (2010) The efficacy of ethyl acetate extract of Trichoderma culture broth on growth inhibition and aflatoxin production by Aspergillus flavus IMI 242684. Curr Appl Sci Technol 10:19-29

Jat J, Agalave H (2013) Antagonistic properties of Trichoderma species against oilseed-borne fungi. Sci Res Rep 3:171-174

Kelly LA, Tan YP, Ryley MJ, Aitken EAB (2017) Fusarium species associated with stalk rot and head blight of grain sorghum in Queensland and New South Wales, Australia. Aust Plant Pathol 66:1413-1423
Köhl J, Kolnaar R, Ravensberg WJ (2019) Mode of action of microbial biological control agents against plant diseases: relevance beyond efficacy. Front Plant Sci 10:845

Koulagi S, Patil M, Shridar D (2011) Evaluation of bio-agents against Curvulara lunata, a causal agent of grain discolouration in rice. Int J Plant Prot 4:260-262

Kumar M, Ashraf S (2017) Role of Trichoderma spp. as a biocontrol agent of fungal plant pathogens probiotics and plant health. Springer, pp 497-506

Kumar M, Vipul K, Meenakshi R, Seweta S (2019) Effect of volatile and non volatile compounds of Trichoderma spp. against Fusarium isolates causing chickpea wilt in Punjab. Plant Archiv 19:159-162

Lari SZ, Khan NA, Gandhi KN, Meshram TS, Thacker NP (2014) Comparison of pesticide residues in surface water and ground water of agriculture intensive areas. J Environ Health Sci Eng 12:11

Little CR, Perumal R, Tesso TT, Prom LK, Odvody GN, Magill CW (2012) Sorghum pathology and biotechnology — a fungal disease perspective: part I. Grain mold, head smut, and ergot. Eur J Plant Sci Biotechnol 6(1):10-30

Munkvold GP (2017) Fusarium species and their associated mycotoxins mycotoxigenic fungi. Springer, pp 51-106

Naglot A, Goswami S, Rahman I, Shrimali DD, Yadav KK, Gupta VK, Rabha AJ, Gogoi HK, Veer V (2015) Antagonistic potential of native Trichoderma viride strain against potent tea fungal pathogens in North East India. Plant Pathol J 31:278-289

Naher L, Yusuf UK, Ismail A, Hossain K (2014) Trichoderma spp.: a biocontrol agent for sustainable management of plant diseases. Pak J Bot 46:1489-1493

Ojha S, Chatterjee NC (2011) Mycoparasitism of Trichoderma spp. in biocontrol of fusarial wilt of tomato. Arch Phytopathol Plant Prot 44:771-782

Perveen K, Bokhari NA (2012) Antagonistic activity of Trichoderma harzianum and Trichoderma viride isolated from soil of date palm field against Fusarium oxysporum. Afr J Microbiol Res 6:3348-3353

Prabhu HV, Adiver S, Bhat R, Narayana Y, Jahagirdar S, Parameshwarappa K (2012) Genetic variability in Macrophomina phaseolina (Tassi.) Goid., causal agent of charcoal rot of sorghum. Karnataka J Agric Sci 25:72-76

Sharma I, Kumari N, Sharma V (2014) Defense gene expression in sorghum bicolor against Macrophomina phaseolina in leaves and roots of susceptible and resistant cultivars. J Plant Interact 9:315-323

Siddiquee S (2014) Recent advancements on the role and analysis of volatile compounds (VOCs) from Trichoderma biotechnology and biology of Trichoderma. Elsevier, pp 139-175

Singh A, Shahid M, Srivastava M, Pandey S, Sharma A, Kumar V (2014) Optimal physical parameters for growth of Trichoderma species at varying $\mathrm{pH}$, temperature and agitation. Virol Mycol 3:127-134

Sreedevi B, Charitha Devi M, Saigopal D (2011) Isolation and screening of effective Trichoderma spp. against the root rot pathogen Macrophomina phaseolina. J Agric Technol 7:623-635

Yago Jl, Roh JH, Bae SD, Yoon YN, Kim HJ, Nam MH (2011) The effect of seedborne mycoflora from sorghum and foxtail millet seeds on germination and disease transmission. Mycobiology 39:206-218

Yassin MT, Mostafa AA, Al-Askar AA (2020a) Anticandidal and anti-carcinogenic activities of Mentha longifolia (Wild Mint) extracts in vitro. J King Saud Univ Sci 32:2046-2052

Yassin MT, Mostafa AA-F, Askar AA (2020b) In vitro anticandidal potency of Syzygium aromaticum (clove) extracts against vaginal candidiasis. BMC Complement Med Ther 20:25

\section{Publisher's Note}

Springer Nature remains neutral with regard to jurisdictional claims in published maps and institutional affiliations. 